\title{
El relato del cadáver de una mujer entre Historia y ficción: Evita
}

La bistoria del odio bacia la mujer es la bistoria del conocimiento de su poder. Jimena Néspolo

\section{Eva Duarte en el imaginario argentino}

Eva Duarte de Perón (Los Toldos, 7 de mayo de 1919 - Buenos Aires, 26 de julio de 1952) despertó en sus escasos años de desempeño en la política argentina, amores y odios, resentimiento y admiración que se sostuvieron en el tiempo transformándose en conflictos y tensiones irresolubles entre clases sociales o posturas ideológicas, incidiendo a su vez en el imaginario de los argentinos. Su estilo de mujer rubia con joyas, vestidos y trajes elegantes, abrigos de piel llamativos y sus peinados con rodetes se volvieron objetos de culto. Desde su aparición en la escena pública, la figura de Eva Perón se tornó objeto de una disputa simbólica que sin duda va más allá de su papel en las políticas del Estado; a la "Evita Santa" se le opuso la "Mujer del látigo", dando forma así a un antagonismo cultural en la historia argentina.

La fuerza de su impronta se manifiesta en las numerosas expresiones artísticas que han tomado su imagen como referente en creaciones y recreaciones tanto en la literatura, como en el cine, la música y otras artes. El musical «Evita» del compositor Andrew Lloyd Webber, transformado en película, bajo la dirección de Alan Park en 1996, con Madonna y Antonio Banderas como actores principales, no solo difundió la canción Don't cry for me Argentina (1976) sino que logró popularizar la existencia de "esa mujer" más allá de los confines de su Patria. Además hay que recordar la instalación de 
Nicola Costantini «Eva Argentina» que se presentó en la Bienal Arte de Venecia de 2013.

En la literatura, su figura se ha considerado desde distintas aristas y acorde con la polarización política del país, pueden establecerse dos posturas acerca de la figura de Evita y de su función, particularmente social, en el gobierno de Perón. Así como en vida fue amada por unos y odiada por otros, tras su muerte seguidores y detractores contribuyeron a la construcción de dos mitos. El mito blanco: el de la santa, el de la mujer sacrificada, el de la Eva que trabajaba a diario, incluso, en los momentos álgidos de su enfermedad, para el bienestar de sus humildes a los que se refería con el apodo de "descamisados". Y el mito negro: el de la prostituta, la ignorante, la advenediza y la ambiciosa, el que impulsaron sus enemigos, los que prohibieron que se la mencionara en público.

En este mismo sentido habría que recordar que en 1956 por Decreto Ley 4161 del 5 de marzo, se penalizó legalmente la mención de los nombres del "presidente depuesto y de su esposa"; esta medida conduce a la referencia elíptica de los mismos en muchos de los relatos de la época. Es el caso, entre otros, de los títulos de los relatos de Onetti «Ella», de Walsh «Esa mujer», de David Viñas «La señora muerta»o «El chasco» de Silvina Ocampo ponen en evidencia y resaltan el absurdo de esta disposición. No es el caso de Borges, quien en «El simulacro» se atreve a transgredir y desafiar la ley, nombrándolos, acaso por la trascendencia de su nombre en el sistema literario argentino (Mancini, 2008: 16). Cuentos, poemas, historietas, obras de teatro y películas han ido configurando una imagen de Evita que responde a ambos extremos de la confrontación ideológica que se generó en esa época y perdura en el tiempo.

Eva Duarte de Perón murió el 26 de julio de 1952 y los avatares que atravesó su cadáver es uno los episodios más oscuros en la historia del siglo XX argentino (Avellaneda, 2002). Fue embalsamada por el doctor Pedro Ara, uno de los expertos reconocido en la época que trabajó intensamente durante meses en un laboratorio montado en la sede sindical de la CGT (Confederación General del Trabajo). El costo fue de cien mil dólares pero el cadáver de Evita se había transformado en una escultura de cera; fue una obra maestra. La CGT, aún hoy un sindicato poderoso, estableció tres días de paro y el gobierno decretó 30 días de duelo. Una procesión multitudinaria, se calcularon más de dos millones de personas, acompañó el cortejo. 
En 1955, Perón fue derrocado por una revolución llamada Libertadora. Desde que asumieron el poder, el cuerpo embalsamado de Evita se convirtió en un objeto conflictivo y a su vez de disputa en el interior de las Fuerzas Armadas. El general Pedro Aramburu decidió ocultarlo y el jefe de inteligencia militar (SIE) Carlos Moori Koenig se encargó de su traslado al cementerio Maggiore de Milán. Sin embargo, el peronismo no la había olvidado. El cadáver de Eva seguía generando rituales, veneraciones, y el reclamo de su paradero era constante. En mayo de 1970, cuando un comando de Montoneros secuestró al general Aramburu, lo interrogaron sobre el cadáver. Aramburu respondió que Eva tenía sepultura cristiana y estaba protegida por el Vaticano, pero no dio precisiones y fue ejecutado.

Alejandro Agustín Lanusse, presidente de facto desde marzo de 1971, decidió la restitución del cuerpo de Eva, en el marco de una negociación política y así lo devolvió a Perón, exiliado en Madrid. Posteriormente, el 17 de noviembre de 1974, después de la muerte de Perón, en un operativo secreto coordinado por López Rega, secretario privado de Perón (y muy cercano a María Estela de Perón alias Isabelita), el cadáver de Evita llegó a Buenos Aires. Hasta 1976 sus restos no fueron traslados al cementerio de La Recoleta, donde hoy descansan.

Han transcurrido más de sesenta años desde su muerte y, aunque es posible que los antagonismos no sean los mismos, el mito no cede el paso al personaje histórico y nuevas configuraciones se construyen en torno a su figura.

Narrar la muerte de Evita y el periplo de su cuerpo fue motivo referencial para escritores y poetas; narrar la vida de Eva Perón, las encrucijadas $\mathrm{y}$ vicisitudes en su función política y social fue, en cambio, tarea de historiadores, ensayistas y biógrafos. Surgen las primeras expresiones en los años setenta, a partir de las aproximaciones de Juan José Sebreli (Eva Perón ¿aventurera o militante?, 1966) y David Viñas («Catorce nuevas hipótesis de trabajo en torno a Eva Perón», 1965) y aparecen biografías más recientes como la de Marysa Navarro (Evita, 1994) y Alicia Dujovne Ortiz (Eva Perón, La madone des sans-chemise, París, 1995, traducida del francés al año siguiente por la propia autora: Eva Perón. La Biografía, Buenos Aires, 1996), entre otras. La literatura representó fundamentalmente el uso de su cuerpo muerto, hilvanando una historia de las apropiaciones reales o simbólicas de ese cuerpo y de las resignificaciones políticas e ideológicas de un cadáver destinado a no morir. 
Emblema de la cultura pop internacional, heroína de Hollywood en la encarnación de Madonna, Eva Perón es también el cadáver fetiche de la literatura argentina, en una saga que se inicia con el relato de Onetti, pasa por la farsa borgeana de «El simulacro» y toma la forma de un cuerpo muerto (que atrae perversamente) en el relato de Rodolfo Walsh. Más allá de una visión "otra" de Néstor Perlongher, diversas formas de aprehender el cadáver de Evita se encuentran en el libro de Alicia Borinsky, Mina cruel (1989); en un capítulo de Historia argentina (1991) de Rodrigo Fresán; en la novela de José Pablo Feinman, El cadáver imposible (1992); en la de Abel Posse, La pasión según Eva (1994); en la de Tomás Eloy Martínez, Santa Evita (1995), de Alicia Dujovne, Eva Perón: la biografía (1996) y de Liliana Bellone, Eva Perón alumna de Nervo (2010) hasta llegar a la novela de Marta Lucía Nesta, Teodora y Evita. Dos vidas, un destino (2019) que se presentó en la feria del libro de Buenos Aires de 2019.

El profesor Loris Zanatta, docente de la Universidad de Bologna, quien escribe Eva Perón. Una biografía politica (2011), sostiene que:

Con la figura de Evita se abre un fascinante fenómeno social en el que la legitimidad popular choca con la institución democrática. La modernización social en Eva se acompañó por un primitivismo político que era impermeable al pluralismo. Su peronismo fue una especie de religión secular con sus dogmas y sus devotos que enredó el mismo tradicional corporativismo de Perón. Este 'puente' religioso sería el anuncio de futuras tragedias ${ }^{1}$.

Aún en la actualidad, el mito se mantiene vital como lo demuestran los homenajes que se van proponiendo; el 19 de febrero de 2019, el vicepresidente de la Cámara de Diputados y presidente del Partido Justicialista de la Nación, José Luis Gioja, presentó un proyecto de ley en ocasión de los 100 años de su nacimiento, donde se pretende declarar el 7 de mayo -fecha de nacimiento de Eva Duarte- "Día Nacional de la Justicia Social". Asimismo, el año 2019 fue declarado por parte de la Legislación de Buenos Aires "Año del Centenario del

1 La versión original en italiano es la siguiente «La figura di Evita schiude un affascinante fenomeno sociale nel quale la legittimità popolare si scontra con l'istituzionalità democratica. La modernizzazione sociale fu accompagnata in Eva da una specie di primitivismo politico impermeabile al pluralismo. Il peronismo di Evita fu una specie di religione secolare, con i suoi dogmi ed i suoi devoti che aggrovigliò lo stesso corporativismo tradizionale di Perón. Questo 'ponte' religioso sarebbe l'annuncio di future tragedia» (Zanatta, 2009: 23). 
nacimiento de Eva Duarte de Perón” y el Consejo Municipal de Rosario propuso el año 2019 como "Año del Centenario del Nacimiento de Eva Perón, jefa espiritual de la Nación".

Un juicio determinante del fenómeno "Evita" es imposible, sin embargo, es interesante señalar la actualidad del tema que sigue provocando todavía hoy fuertes enfrentamientos y que en aquel entonces logró despertar por primera vez la conciencia de clase entre los más pobres ( $c f r$. Altamirano: 2011).

La mitificación del personaje por la literatura, o más bien, lo contrario, el principio de des-mitificación, puesto que varios de los textos pueden ser vistos como la tentativa de distanciarse «de la veneración fetichista», empieza precisamente con el relato de Onetti. Inmediatamente aparecen otros, entre los cuales «El simulacro» (1960) de Borges que se asocia semánticamente con «El chasco» de Silvina Ocampo (1970) puesto que ambos ponen en escena el funeral de una señora rubia de un pueblo del interior como una gran farsa; «La señora muerta» (1963) de David Viñas, texto que minimiza la solemnidad de la escena mortuoria donde la gente hace la cola durante muchas horas para poder ver el cuerpo de la difunta; «Esa mujer» (1965) de Rodolfo Walsh, que elabora un relato policial, cuyo título tiene un significado especial que se explica con la frase final del uno de los protagonistas donde "esa" remite a la "única", a la deseada por todos (Mancini, 2008), sin olvidar los dos poemas de Néstor Perlongher, «El cadáver» (1980) y «El cadáver de la nación” (1989). Otros títulos son «Eva Perón» (1970) de Copi, «La cola» (1982) de Fogwill junto con las citadas novelas de Tomás Eloy Martínez y de Abel Posse. Por último, quiero recordar el cuento de Rodrigo Fresán «El único privilegiado» $(1991,1993)$ que se publicó también en italiano el 28 de diciembre de 2018 con el título «Il grande bugiardo» en un número especial de Internazionale dedicado a la narrativa argentina contemporánea, relato, una vez más, dedicado al cuerpo muerto de Evita.

Se trata de narraciones que en su mayoría insisten en focalizar el cuerpo muerto y ofrecen en su conjunto una sumatoria de puntos de vista que conforman un retrato multifacético de una mujer multifacética: la "trepadora más o menos indecente", una estrella, una niña frágil e inocente (sus primeros papeles en el cine juegan con ese aspecto), una mujer del pueblo, la Primera Dama, apasionada, dulce y materna. Durante la enfermedad de cáncer que padeció muy joven se resaltó la imagen de luchadora y, en este sentido, se recupera su figura de mártir entregada a su pueblo. 


\section{2 «Ella» de Juan Carlos Onetti}

En 1953 Juan Carlos Onetti (Montevideo, 1909 - Madrid, 1994) escribe «Ella», un relato corto publicado tardíamente, en 1994, en una reedición de sus Cuentos completos. El texto narra la muerte de Eva Perón y la decisión de embalsamar su cadáver ${ }^{2}$. «Ella» inaugura una larga tradición literaria que toma como materia la mitificación e inscripción en la inmortalidad del cuerpo de la mujer más famosa del país; que se convertirá en el mito femenino argentino por excelencia alcanzando dimensión internacional.

Susana Rosano en su ensayo sobre "Ella" de Juan Carlos Onetti. Necrofilia y ficción» escribe acerca de los recuerdos de Onetti como testigo de la monumental honra fúnebre dedicada a Eva Perón en 1952. Onetti se encontraba en Buenos Aires como corresponsal de la agencia de noticias Reuters y definió la situación como una «necrofilia en masa» (Rosano, 2009: 6).

El relato de Onetti es el primero de un conjunto fecundo de textos de otros autores que trabajan a partir de lo que Rosano define como «la escritura cadavérica» (2009: 6) en torno a las representaciones sobre la muerte de la primera dama de la nación ${ }^{3}$. Lo curioso es que a pesar de no publicarse en el momento de su creación, el relato anticipa y resume muchos tópicos que volverán a encontrarse en los relatos que se escribirán después, a lo largo de más de cincuenta años. Las obras literarias sobre Eva Perón como las cinematográficas, visuales o teatrales «se han convertido en una de las claves para pensar una buena parte de la literatura argentina en diálogo con la historia cultural del país, sus mitos y sus formaciones culturales» (Saítta, 2008: 3). En efecto, el personaje de Evita se convierte en el objeto de una mitología que genera una desbordante proliferación documental sobre esta mujer, que abarca todos los géneros imaginables y que hace de ella un «artefacto cultural» que a lo largo de los años compite por escribir la inmortalidad de su cuerpo. Se trata de una proliferación iconográfica y textual, que

2 «Su muerte, ocurrida en 1952, sirvió para marcar un hito divisorio entre dos etapas. Cuando media Argentina lloraba por ella, el proyecto de 1946 llegaba a su fin» (Sidicaro, 1996: 42).

Mientras el pueblo velaba a Evita en el Ministerio de Trabajo, un equipo de técnicos y de obreros había transformado el segundo piso de la central obrera en un laboratorio para que Ara pudiera completar el embalsamiento del cuerpo. Después de que lo trajeran a la CGT, las puertas del segundo piso se cerraron al público. Envuelto en el más completo secreto, guardado por efectivos de la Gendarmería Nacional y miembros de la CGT, Ara trabajó durante casi un año y el resultado final fue aprobado por una comisión compuesta por los doctores Finochietto, Cámpora y Mendé. En el mes de julio de 1953, Ara comunicó a la Comisión Nacional del Monumento a Eva Perón que había concluido el embalsamiento del cuerpo de Evita. 
multiplica los sentidos y hace del personaje una mujer que se transforma en muchas personas. Curiosamente es, sobre todo, la literatura la que se ocupa de su cuerpo muerto, mientras que la historia o el cine tratan el conjunto de su existencia.

En el breve cuento de Onetti no se mencionan los nombres de Eva Duarte ni de Juan Domingo Perón, a los que se alude simplemente como «Ella»y «Él», con mayúsculas, esto se relaciona con la prohibición de nombrarlos ya comentada. El relato se centra en los últimos momentos de la agonía de Evita $\mathrm{y}$ en las primeras manifestaciones de las multitudes a las que se las describe como «miles y miles de necrófilos murmurantes y enlutados» (s.p.) que se amontonan en las puertas del Ministerio de Trabajo donde serán velados los restos de la mujer y que lograrán finalmente avanzar a la mañana del día siguiente «dos metros cada media hora» $\mathrm{y}$ «en grupos de cinco, empujados y golpeados» (s.p.) para verla.

La narración empieza con un juego que tensiona el enfrentamiento de los dos grupos. En primer lugar los ricos que festejan la muerte de la mujer: «cuando Ella murió después de largas semanas de agonía y morfina, de esperanza, anuncios tristes desmentidos con violencia, el barrio norte cerró sus puertas y ventanas, impuso silencio a su alegría festejada con champán» (s.p.) y, más adelante, el pueblo que «provenía de barriadas desconocidas por los habitantes de la Gran Aldea, de villas miseria, de ranchos de lata, de cajones de automóviles, de cuevas, de la tierra misma, ya barro. Ensuciaban la ciudad silenciosos y sin inhibiciones, encendían velas en cuanta concavidad ofrecieran las paredes de la avenida ...» (s.p.). Otra contraposición se establece entre los cinco médicos que acompañan la agonía de la mujer, en el piso superior de la casa presidencial y el otro médico que espera abajo ${ }^{4}$. Ellos son profesionales, devotos de la Iglesia Católica, que se oponen a los deseos de inmortalización del embalsamador que «era un Catalán, embalsamador de profesión conocida y llamado por Él desde hacía un mes para evitar que el cuerpo de la enferma siguiera el destino de toda carne» (s.p.). Se alude así al aragonés Pedro Ara, médico y anatomista, con suficiente experiencia en la inusual tarea de embalsamar cadáveres cuyo único objetivo era cumplir el

4 A este respecto es interesante recordar el libro de Nelson Castro, Los últimos días de Eva. Historia de un engaño, que relata de los muchos silencios que rodearon la enfermedad de la primera dama argentina. 
mandato de Perón. Ara trabajaba en la embajada española en Buenos Aires como adjunto cultural's.

A través de esta contraposición se ironiza sobre la tensión entre la práctica momificadora y las leyes de la Iglesia Católica, que solo considera la inmortalidad del alma y por consiguiente admite para el cuerpo un destino de putrefacción. Precisamente en este punto de la pudrición que se espera del cuerpo, se señala el tópico del mal olor que también comparten los simpatizantes y los detractores del peronismo. Los primeros, gente pobre que espera para ver el cadáver, ofrecen «el mal olor de las gastadas ropas de luto improvisado» (s.p.) y los segundos, integrantes del barrio norte que festejan con champán su alegría, todavía guardan «el olor a bosta» en una irónica alusión a la procedencia pecuaria de la oligarquía ganadera. Sin embargo, todos coincidían en afirmar la belleza de la muerta puesto que «Ella había sido infinitamente más hermosa que las gordas señoras, sus esposas [de la oligarquía]» (s.p.). El mismo elemento del deterioro y la putrefacción vuelve al final del relato cuando la multitud popular advierte que «tiene la frente verde. Cierran para pintarla» (s.p.).

Otro elemento que es interesante relevar es la feminización de la multitud, largas colas en el desfile que en su callada obstinación deben soportar todo tipo de humillaciones puesto que «los golpes preferidos por los milicos eran los rodillazos buscando los ovarios, santo remedio para la histeria» (s.p.). De esta forma el cuerpo social se confunde con el cuerpo de la mujer, a través de la percepción del desborde en ambos, simbolizado por la histeria, estableciendo una síntesis entre lo político y lo sexual, unidos por el desprecio hacia lo

5 «Ara ha muerto y según su propia voluntad, ha salido a la luz lo que él vivió con el cuerpo de la rubia argentina durante 40 meses y lo que posteriormente acaeció en Madrid, el sábado 4 de septiembre de 1971, durante la ceremonia de reconocimiento de la momia preparada por él 16 años atrás. Durante el destapamiento del féretro estuvieron presentes Perón, su esposa Isabel Martínez. Antonio López Rega, hombre de confianza del general y el embalsamador. [...] La verdad era que, en un solitario lugar del segundo piso de la Unión General de Trabajadores en Buenos Aires, el doctor Ara, con su personal técnico, trabajaba en secar y endurecer el cuerpo, conservando intactas sus características. El experto terminó su obra cuando el dueño, Perón, había caído del poder y entonces su solitario trabajo fue comprobado por investigadores del presidente Aramburu. Comenzaron las pruebas histológicas, radiografías, análisis y, en última instancia, la certificación de que aquel cuerpo de expresión dulce y serena que conservaba absolutamente todos sus órganos y que no había sido sometido a desgarres ni incisiones, era el de María Eva Duarte de Perón. El profesor Nerio Rojas hizo un pequeño corte en la oreja derecha del cadáver para el estudio histológico. También le seccionaron parte de un dedo para comprobar las huellas digitales», explica Ara en su obra póstuma. Este había decidido, y lo cumplió, no hablar a nadie del paréntesis de su vida durante 40 meses. El libro que escribió, titulado El Caso Eva Perón, acaba de salir al público en España, después que su autor murió en Buenos Aires en 1973 (Villalba, 2017: s.p.). 
femenino. En este sentido, Rosano escribe: «Eva, al igual que las masas populares, estaría cerca de la irracionalidad de la barbarie» (s.p.). Asimismo, la descripción del historiador Tullio Alperin Donghi es similar:

De nuevo una muchedumbre, ahora silenciosamente paciente, invade el centro de Buenos Aires; espera a lo largo de horas el momento en que podrá contemplar, bajo cristal y envuelta en los reflejos violáceos de una sabia iluminación, a la que fue a la vez Dama de la Esperanza y la Abanderada de los trabajadores, personificación del Nuevo Estado por primera vez benévolo a las capas populares, pero a la vez de esas capas mismas, del rencor acumulado en su largo silencio por un pueblo acaso demasiado manso. (Sidicaro 1996: 48)

En la obra se pueden rastrear todos los tópicos que a lo largo de unos sesenta años escritores y artistas han desarrollado en sus creaciones, especialmente la puesta en escena de un cadáver joven y bello. Lo que en este relato se vislumbra es la belleza y el deseo de los enemigos que la consideraron mucho más hermosa que sus mujeres junto con la veneración de las masas de los desposeídos que vieron en ella la protectora entre diosa y santa.

Este elemento vuelve y se reafirma en otros escritores como Walsh y Fresán en sus respectivos relatos «Esa mujer» (1966) y «El único privilegiado» (1991) donde se narra el deseo de un hermoso y joven cuerpo muerto.

\section{3 «Esa mujer» de Rodofo Walsh}

Los oficios terrestres es una compilación de seis textos publicados en 1965, encabezado por «Esa Mujer», donde el autor, Rodolfo Walsh (Lamarque, 1927 - Buenos Aires, 1977), mezcla el policial, lo histórico en versión literaria y el periodismo, elementos que consigue sintetizar en este cuento, considerado uno de los más importantes de la historia literaria argentina del siglo XX. Como en todos sus trabajos, Walsh se muestra aquí obsesionado por la estética y la precisión de las palabras. A este respecto declaró que: «Comencé a escribir "Esa mujer" en 1961, lo terminé en 1964, pero no tardé tres años, sino dos días: un día de 1961, un día de 1964» (Güichal, 2004: 27). «Esa mujer» presenta la deuda con el reconocido texto anterior del autor Operación Masacre (1957), el largo reportaje que se lee como una novela y que supone el hito fundacional del periodismo narrativo o de la no-ficción como lo llamó Ana María Amar Sánchez (1990) en Latinoamérica, años antes de que Truman Capote publicara A sangre fría (1965) e inaugurara lo que se conoce como New Journalism. 
El tema del relato se concentra en la búsqueda del cadáver de Evita Perón por parte de un periodista (el texto da a entender que se trataría del proprio Walsh) y de su encuentro con un coronel, el supuesto coronel Moori-Koening, que sabe dónde está escondido y remite a la larga historia de las peripecias que este cuerpo embalsamado sufrió a lo largo de años 6 . Se narra el diálogo entre estos dos hombres antagonistas y adversarios ideológicamente, que se sientan a la misma mesa en el ámbito cerrado del escritorio del coronel uno de ellos. El periodista/narrador adelanta enseguida su propósito «yo busco a una muerta, un lugar en el mapa» (s.p.). Los datos diseminados dan verosimilitud a la entrevista que tiene lugar en el relato. El diálogo continúa, cada vez más seco y escueto, es una conversación extraña en la que nunca se nombra el objeto

6 El cuerpo embalsamado de Eva Duarte se convirtió en un problema para el gobierno y probablemente por razones religiosas el gobierno militar no quiso deshacerse de él. La solución que adoptó fue enterrarlo secretamente. El 23 de noviembre comenzó el operativo dirigido por el teniente coronel Carlos Eugenio Moori Koenig, jefe del Servicio de Informaciones del Ejército. «A una señal mía», relata Ara, «dos obreros se acercaron para ayudarme. Uno de ellos, sin descubrirla, la levantó tomándola con su túnica por los tobillos; entre el otro y yo la levantamos por los hombros. Y así transportamos su delgado cuerpo, lentamente, con sumo cuidado, de la plataforma al fondo del ataúd, sin desordenar su peinado ni su vestido, quedando bien patente sobre él la cruz de su rosario» (Ara, 1974: 56). Eran las dos de la madrugada y a pesar de la insistencia de Ara, el ataúd no fue soldado esa noche ni al día siguiente como prometió Moori Koenig, ni nunca. El teniente coronel no se puso más en contacto con Ara y se le prohibió la entrada a la CGT. Unas semanas más tarde una voz misteriosa le anunció por teléfono: -Profesor: ya se la llevaron (Navarro, 1994: 277-289). [...] La restitución del cuerpo de Evita ya formaba parte en este período de la estrategia política del peronismo. Pero el surgimiento de Montoneros y de otras "formaciones especiales", nombre que le dio el peronismo a sus grupos guerrilleros, marcó también la aparición de otro nuevo mito de Evita. Se entronca con la Evita combativa y militante que había predominado en los sectores gremiales del peronismo durante La Resistencia, pero ahora se extiende a sectores de clase media. Con el trasfondo de luchas populares como la del Cordobazo, se va forjando poco a poco el mito de Evita militante, la mujer que ha nacido para la Revolución, la enemiga de la oligarquía, que no se deja doblegar ante nada. Se rescatan así sus frases más combativas, las de sus últimos discursos, en los que pide al pueblo que cuide a Perón, que lo defienda de sus enemigos, que luche por él y por su causa, y se convierten en consignas que se adecuan a la estrategia del peronismo para obtener el retorno de Perón a la Argentina y volver al poder. Esta nueva Evita, apasionada y revolucionaria, no desplaza el mito de la Evita Santa, sino que coexiste con él. Cabe señalar solamente que poco tiempo después de asumir la Presidencia, el teniente general Alejandro Agustín Lanusse se mostró dispuesto a cerrar el ciclo iniciado en setiembre de 1955 permitiendo que el peronismo se reintegrara a la vida política del país y tomara parte en las elecciones presidenciales anunciadas para 1973. El 4 de setiembre de 1971, su embajador en Madrid entregó a Perón el cuerpo de Evita (Navarro, 1994: 279). El 17 noviembre de 1974, fue traído finalmente de vuelta a la Argentina y en 1976, el nuevo gobierno militar entregó el cuerpo de Evita a su familia, que finalmente lo enterró en el cementerio de La Recoleta (Navarro, 1994: 280). 
central del interés de los dos: el cadáver de la mujer más importante del país. El estilo del relato cambia cuando el periodista intuye que es posible reunirse con el objeto de su búsqueda: «Si la encuentro frescas altas olas de cólera, miedo y frustrado amor se alzarán, poderosas vengativas olas y por un momento ya no me sentiré solo, ya no me sentiré como una arrastrada, amarga, olvidada sombra» (s.p.). A este propósito Marcelo Méndez señala que «el texto sugiere una imantación que parece formar parte del potencial mítico. Presenta un tono 'medio', desde el que se eleva ante una hipotética aproximación del mito y desde el que desciende cuando el mito parece alejarse» (Méndez, 2008: 33). Cambios que ponen en evidencia la ausencia del nombre y, al mismo tiempo, alimentan el mito.

El enfrentamiento continúa con la ocasional presencia de la mujer del coronel, muda y sometida, que narrativamente tendría como función marcar un contraste que refuerza la potencia de la figura femenina ausente.

El mito se subraya cuando se alude a la creencia popular acerca del poder de Evita para castigar a quienes habían saqueado su cadáver. El coronel relativiza esta opinión y el periodista la sostiene. La conversación continúa a través de las quejas del militar por las amenazas recibidas y por el atentado con una bomba que había estallado en el palier de la vivienda del coronel. Es en este punto en el que el odio hacia el pueblo se desencadena mediante un antiperonismo elemental donde el coronel se considera víctima de «esos roñosos (que) no saben lo que yo hice por ellos» y que además «no es que me importe quedar bien con esos roñosos, pero sí ante la historia» (s.p.). La fuerza discursiva del militar va decayendo hasta ser un grito descarnado que exalta el vigor de la figura de Evita en tanto mito: «Esa mujer ... estaba desnuda en el ataúd y parecía una virgen [...] ya le dije que esa mujer estaba desnuda. Una diosa y desnuda y muerta [...] uno se desmayó. Lo desperté a bofetadas. Le dije: maricón. ¿jesto es lo que hacés cuando tenés que enterrar a tu reina? Acordate de san Pedro que se durmió cuando lo mataban a Cristo» (s.p.), para concluir en un crescendo: «¡Está parada! La enteré parada como Facundo porque era un macho» (s.p.). La cadena de términos - virgen, diosa, reina y macho- remiten a una valorización positiva -el macho era Perón- que valora y reafirma el potencial del mito poniéndolo de manifiesto. Es acertada la elección del narrador de otorgar a un coronel furioso antiperonista la posibilidad de expresar su embelesamiento por esa mujer muerta.

Al final del relato el tenor del enfrentamiento de los antagonistas se deteriora. El coronel que ha acompañado la conversación con varios vasos de whisky, 
oscila entre la exultación de poseer el cuerpo y la culpa del lugar que la Historia le tiene reservado. El vigor con el que bebe al principio se transforma: «bebe con ira, con tristeza, con miedo, con remordimiento» (s.p.), rompiendo la simetría de dos hombres enfrentados para restablecer la asimetría de relación de poder entre un representante de la revolución liberadora y un representante del peronismo proscripto que subyace en el texto.

Las palabras del coronel que cierran el texto son determinantes: «Es mía, dice simplemente. Esa mujer es mía» (s.p.). Es la afirmación final de un militar borracho frente a un periodista derrotado que, una vez más, despliega el potencial de Eva Perón.

La relación de la narración de «Esa mujer» con el libro Operación Masacre se debe al hecho de que, como escribe el autor en la «Nota» que lo precede, «la conversación que reproduce es, en lo esencial, verdadera» (Walsh, 1965: s.p.) y remite a la frontera siempre ambigua entre escritura periodística y narración de ficción donde se ubican algunas de las obras de Walsh. Como señala Marcelo Méndez, Walsh aprovecha al máximo el hecho de destacar los aspectos reales del texto y trabajarlos literariamente (Méndez, 2008: 32). También aquí es importante remarcar lo no dicho, la elipsis, que en este caso constituye el elemento formal determinante porque lo que se omite es precisamente el nombre de la protagonista: Evita. A través de esta estrategia se subraya el carácter mítico del personaje que se transforma en el eje central de la narración.

\section{4 «El único privilegiado» de Rodrigo Fresán}

Tampoco en el relato de Rodrigo Fresán (Buenos Aires, 1963), «El único privilegiado» (1991), aparece el nombre de Eva Perón y se pueden encontrar coincidencias con el texto de Walsh, según declara el mismo autor en «El cuento por su autor», un artículo publicado el 27 de febrero 2011 en la revista Página/12:

Lo primero que se me ocurrió - suele ocurrirme- fue el título. A continuación, el epígrafe de Joseph Conrad. Y las ganas de terminar invocando el In the Mood de Glenn Miller. Después, enseguida, la soberbia entre audaz e irresponsable de componer una variación sobre el aria de uno de los cuentos legendarios de nuestra literatura: «Esa mujer», de Rodolfo Walsh. Lo que siempre admiré de ese relato -además de su ritmo seco y su atmósfera casi sobrenatural que evoca a «La pata de mono», 
de W. W. Jacobs- es lo que allí consigue Walsh. La hazaña de primero plantar uno de esos cuentos de fantasmas sin fantasma de Henry James en el que alguien le cuenta algo a alguien para después hacerlo hablar en el idioma del mejor Ernest Hemingway. «Esa mujer» sigue funcionando igual de bien que el primer día. Es uno de esos textos que no va a desaparecer nunca. (Fresán, 2011b: s.p.)

«El único privilegiado» es uno de los textos que tras la desaparición de la última dictadura evoca la figura de Evita y que se escribe en un momento histórico distinto con respecto a los escritos presentados en la primera parte de esta lectura. En el relato, un conocido mentiroso cuenta al narrador cómo en su adolescencia tuvo, sin saberlo, la ocasión de acostarse -por error, pues lo creía el cuerpo de su amada Mónica, la hija natural del padre, "dama de compañía del joven"- con el cadáver embalsamado de "la abanderada de los pobres", cuerpo que su padre -un militar que remite al que se encuentra en el relato de Walsh, posiblemente el mismo Moori-Koening- ha guardado en su casa durante un tiempo. Según Sylvia Saitta se trata de la «primera representación del cadáver inerte [...] donde el cuerpo de Eva sirve de iniciación sexual a un adolescente de clase alta (en franca oposición al cuerpo de Evita en la orgía de los lúmpenes (del cuento de Perlongher)»(Saitta, 2002: 10). Como señala Fresán:

«El único privilegiado»-que empecé y terminé a lo largo de una tarde de sábado, de ahí que lo escoja para estas páginas de lectura veloz y pasajera- acabó en mi primer libro, Historia argentina, 1991, y ahí sigue yaciendo y descansando más o menos en paz. En alguna parte, bajo mármol y acero y tierra, underground, el polimorfo y perverso y multifuncional cadáver de esta hembra que aquí pone el cuerpo vuelve y es millones y sigue dando de qué hablar y de qué escribir. No fui el primero y, seguro, no soy ni seré el último en oír el atronador silencio de su voz. (Fresán, 2011b: s.p.)

A la Evita que se narra en los años setenta se opone la verdadera momificación del personaje en los años noventa. La literatura capta muy tempranamente que los tiempos del peronismo menemista no necesitan de 'cadáveres de la Nación' que se mantengan vivos. La representación del cadáver inerte que aparece en «El único privilegiado» (1991), de Fresán, relata sobre el cuerpo muerto de Eva Perón que sirve de objeto sexual para la clase alta en total contraposición al cuerpo vivo de Evita que fue el ídolo de las clases populares. 


\section{Conclusiones}

Con respecto a los textos considerados, es interesante señalar la preeminencia de lo no dicho a través del recurso a la elipsis, estrategia formal determinante para la construcción de este mito que remite a la consabida afirmación de Barthes quien señala que «la literatura comienza [...] ante lo innombrable» (Barthes, 1957: 34).

Todas estas obras presentan distintas maneras de enfocar la representación del cadáver de la primera dama del peronismo en sintonía con el cuento de Onetti. Motivos diversos como la descomposición, el tópico del mal olor, la impostura del cuerpo embalsamado por parte del mandatario, el entrelazamiento entre lo político y lo sexual en la escena del velorio y la imagen de Eva como una diosa, pero también como un siniestro cadáver, son elementos que participan de la construcción del mito cuya potencia se sostiene.

La pregunta que surge al estudiar estos textos es la del motivo de esta recurrencia a la figura de Eva Perón y a sus representaciones literarias, teatrales, cinematográficas, visuales, etc. Naturalmente no hay una sola respuesta, se pueden proponer solo algunas hipótesis. La primera es que hay que destacar que se trata de escritores argentinos o rioplatenses como Onetti y que esta elección tiene mucho que ver con la historia política y cultural del país. Se puede añadir que, además de ser el cadáver fetiche de la literatura nacional, resulta interesante estudiar los elementos que demuestran que el producto final "Evita" es una suma de estrategias de representación que tienen una finalidad política. Más relacionado con lo literario, hay que resaltar que los cambios en los paradigmas teóricos y críticos encuentran en las representaciones de esta mujer un corpus denso como para abordar nuevas problemáticas relacionadas con las cuestiones vinculadas al género, a la identidad política, y a los estudios sobre el cuerpo.

Finalmente y volviendo al primer relato presentado, «Ella» de Juan Carlos Onetti donde se lee: «Según la pequeña historia, tantas veces más próxima a la verdad que las escritas y publicadas con $\mathrm{H}$ mayúscula ...» (s.p.) una vez más hay que resaltar como el relato de la literatura logra comunicar las verdades que el dato de la Historia no alcanza. 


\section{Bibliografía}

Altamirano, C. (2011): Peronismo y cultura de izquierda. Buenos Aires: Siglo XXI eds.

Amar Sánchez, A. M. (1990): «La ficción del testimonio». Revista Iberoamericana, 56/151, 447-461.

Ara, P. (1974): El caso Eva Perón (apuntes para la bistoria). Madrid: CVS Ediciones.

Avellaneda, A. (2002): «Evita: cuerpo y cadáver de la literatura». En: M. Navarro (comp.): Evita. Mitos y representaciones. Buenos Aires: Fondo de Cultura Económica, 101-141.

Barthes, R. (1957) : «La Littérature selon Minou Drouet». En: Mytbologies. Paris: Seuil, 134-151.

Castro, N. (2008): Los últimos días de Eva. Historia de un engaño. Buenos Aires: Sudamericana.

Fresán, R. (1991): «El único privilegiado». En: Historia argentina. Barcelona: Anagrama, 43-51.

Fresán, R. (1993): Historia argentina. Buenos Aires: Anagrama.

Fresán, R. (2011a): «El único privilegiado». Página/12, 27 de febrero: https:// www.pagina12.com.ar/diario/verano12/23-163137-2011-02-27.html (10-11-2019).

Fresán, R. (2011b): «El cuento por su autor». Página/12, 27 de febrero: https:// www.pagina12.com.ar/diario/verano12/subnotas/23-52251-2011-02-27. html (10-05-2020).

Fresán, R. (2018): «Il grande bugiardo». Internazionale, 28 de diciembre, 28-31.

Güichal, C. (2004): Viaje a la escritura. Bahía Blanca: EDIUNS: books.google. com.pr/books? id=GCJbwKipkYC\&printsec=copyright\#v=onepage\&q\&f =false (28-04-2019).

Mancini, A. (2008): «Silvina Ocampo: "El chasco", la inquietud y la historia». En: S. Saítta (comp.): Algunas representaciones de Eva Perón en la literatura argentina. Buenos Aires: Universidad de Buenos Aires, Facultad de Filosofía y Letras, 13-18.

Méndez, M. (2008): «La dama desaparece: apuntes sobre la representación de Eva Perón en "Esa mujer" de Rodolfo Walsh» En: S. Saítta (comp.): Algunas representaciones de Eva Perón en la literatura argentina. Buenos Aires: Universidad de Buenos Aires, Facultad de Filosofía y Letras, 31-36. 
Navarro, M. (1994): Evita. Buenos Aires: Planeta.

Néspolo, J. (2015): Episodios de cacería. Buenos Aires: Santiago Arcos editor.

Nesta, M. (2019): Teodora y Evita. Dos vidas, un destino. Buenos Aires: Editorial Vuelta a casa, Instituto Federal de Historia argentina e iberoamericana Coronel del Pueblo Manuel Dorrrego.

Onetti, J. C. (1994): «Ella». En: Cuentos Completos (1933-1993). Madrid: Alfaguara.

Onetti, J. C. «Ella»: https://www.literatura.us/onetti/ella.html (28-04-2019).

Rosano, S. (2009): «"Ella” de Juan Carlos Onetti. Necrofilia y ficción». Kipus: revista andina de letras. 26, 5-17.

Saítta, S. (2002): «Eva Perón: De actriz a personaje literario». La Nación, 17 de julio, 14-17.

Saítta, S. (2008): «Introducción». En: S. Saítta (comp.): Algunas representaciones de Eva Perón en la literatura argentina. Buenos Aires: Universidad de Buenos Aires, Facultad de Filosofía y Letras, 3-6.

Sidicaro, R. (1996): Los nombres del poder. Juan Domingo Perón. La paz y la guerra. Buenos Aires: Fondo de Cultura Económica.

Walsh, R. (1965): Los oficios terrestres. Buenos Aires: Jorge Álvarez.

Walsh, R. (1965): «Esa Mujer»: http://www.fadu.uba.ar/post/412-171-esamujer-rodolfo-walsh (10-02-2020).

Villalba, I. (2017): «El hombre que embalsamó a "Evita" Perón»: https:// it.scribd.com/document/437061161/El-hombre-que-embalsamo-a-EvaPeron (10-02-2020).

Zanatta, L. (2009): Eva Perón. Una biografia politica. Cosenza: Rubbettino.

Zanatta, L. (2011): Eva Perón. Una biografía política. Trad. C. Catroppi. Buenos Aires: Sudamericana. 


\section{Between history and fiction: Evita, the story of a woman's body}

Keywords: history, narration, rewrites, Onetti, Evita

The story of Eva Duarte de Perón (1919-1952) has inspired popular imagination round the world and has been the subject of numerous creations and recreations in literature, film and music; it has kindled love and provoked hate. On the occasion of the recent centenary of the birth of Eva Perón in 2019, we propose to study some stories written over the past sixty years on the subject of the body of Argentina's most famous woman. Taking as the starting point Juan Carlos Onetti's "Ella", the first such story which was written in 1953 and published in 1994 and which narrates the death of Eva Perón and the decision to embalm her body, the article studies Rodolfo Walsh's "Esa mujer" (1965) and Rodrigo Fresán's "The Only Privileged One" (1991). Onetti's story inaugurates a long literary tradition, which takes as its subject the mythification and immortalisation of the body of this Argentine female legend, and also anticipates a series of recurring motifs in the later treatments of the subject.

\section{Zgodba o truplu neke ženske med zgodovino in fikcijo: Evita}

Ključne besede: zgodovina, pripoved, predelave, Onetti, Evita

Zgodba Eve Perón (1919-1952) je zbudila ljudsko domišljijo po vsem svetu ter je bila predmet stvaritev in poustvaritev v književnosti, filmu in glasbi. Sprožala je ljubezen in sovraštvo. Ob nedavni stoletnici rojstva Eve Duarte Perón prispevek izpostavlja nekaj zgodb, ki so bile napisane v zadnjih šestdesetih letih o truplu najslavnejše ženske $v$ Argentini. Izhodišče analize je zgodba »Ella« [Ona] Juana Carlosa Onettija, ki je bila napisana leta 1953 in objavljena 1994 ter pripoveduje o smrti Eve Perón in odločitvi, da je treba njeno truplo balzamirati, »Esa Mujer« [Tista ženska] (1965) Rodolfa Walsha in »El único privilegiado« [Edini privilegiranec] (1991) Rodriga Fresána. Onettijeva zgodba odpira dolgo literarno tradicijo, ki jemlje za snov mitifikacijo argentinskega ženskega telesa par excellence in njegov vpis $v$ nesmrtnost ter anticipira niz motivov, ki se ponovno znajdejo v različnih poznejših različicah. 


\section{Susanna Regazzoni}

Susanna Regazzoni es catedrática de literaturas hispanoamericanas en la Universidad Ca' Foscari de Venecia y directora del Archivio Scritture Scrittrici Migranti de dicho ateneo. Dirige asimismo Diaspore. Cuaderni della ricerca, serie de Ca' Foscari Edizioni y es miembro de redacción de varias revistas. Sus intereses de investigación se centran en las literaturas española e hispanoamericanas de los siglos XIX, XX, XXI, con especial atención a los estudios de género, la construcción de la identidad cultural en el siglo XIX, las relaciones culturales Italia - Argentina, las características del discurso literario en Cuba y en Argentina. Entre sus últimos libros publicados se cuentan Escritoras hispanoamericanas del siglo XIX (Cátedra, 2012), Entre dos mundos. La condesa de Merlín o la retórica de la mediación (Beatriz Viterbo, 2013), Osvaldo Soriano. La añoranza de la aventura. Una perspectiva exterior (Katatay, 2017) y junto con Carmen Domínguez Gutiérrez ha cuidado la edición de L'altro sono io. Scritture plurali e letture migranti / El otro soy yo. Escrituras plurales y lecturas migrantes ( $\mathrm{Ca}$ ' Foscari Edizioni, 2020).

Dirección:

$\begin{array}{ll} & \text { Ca'Bernardo-Dorsoduro } 3199 \\ & 30123 \text { Venezia } \\ & \text { Italia } \\ \text { Correo electrónico: } & \text { regazzon@unive.it }\end{array}$

